\title{
Integrated Fibre-Optic Sensor Networks as Tools for Monitoring Strain Development in Bridges during Construction
}

\author{
Liam J. Butler, Niamh Gibbons, Campbell Middleton and Mohammed Z.E.B. Elshafie \\ Department of Engineering, University of Cambridge, UK \\ Contact: lb643@cam.ac.uk (Liam Butler)
}

\begin{abstract}
Long-term asset management and maintenance of civil infrastructure relies on having access to reliable performance data in order to inform critical decision-making processes. This paper discusses the development and implementation of a robust, innovative and highly distributed fibre-optic sensor network for use as a bridge monitoring and performance evaluation tool. The main steel girders of a new 26.8 metre span half-through steel railway bridge were each instrumented with 80 fibre Bragg grating (FBG) based sensors (spaced at 1 metre) prior to the casting of the concrete deck. Two major challenges with implementing fibre-optic monitoring systems remain prominent: appropriately compensating for strain changes due to temperature, and designing the system to be sufficiently robust to survive installation and continuous long-term operation. This study addresses these challenges through the implementation of a new temperature compensation sensor cable packaging and the deployment of glass-fibre reinforced strain FBG sensor cables with the aim of improving overall network reliability. The completed system is capable of measuring the dynamic strain of all installed FBG sensors simultaneously at sampling rates of $250 \mathrm{~Hz}$ to strain resolutions within \pm 10 microstrain. Data was collected and initial results are presented for the strain developed within the main girders during the casting and curing of the concrete deck. The sensor readings captured the quasi-distributed profile of strains developed along the main girders due to the casting and curing of the concrete deck and have provided insights into understanding the complex thermal response of the structure. This study demonstrates that integrated structural health monitoring systems installed at the time of construction can provide a complete record of the entire load history of a structure. Performance data of this type is invaluable for understanding the behaviour of composite concrete decks, evaluating future structural capacity, establishing long term monitoring programmes, and allowing performance-based asset management decision making.
\end{abstract}

Keywords: Bridges; fibre optic sensors; fibre Bragg gratings; railway infrastructure; structural health monitoring.

\section{Introduction}

There are two main practices of installing structural health monitoring systems in structures: installations on existing structures at some instance during their design life and installations in new structures from the moment they are constructed. The installation of SHM systems on existing structures typically arises to address the questions over the remaining load carrying capacity of the structure. However, the flexibility of how and where the SHM system (e.g. sensors) can be installed on an existing structure is limited. Furthermore, structural analysis using these types of systems can become difficult as the load history (baseline values of stresses, strains, etc.) prior to 
installation of the system is unknown (Webb 2014). In systems installed during construction, a higher degree of flexibility in system placement and configuration is possible, particularly so if the system is incorporated within the initial design phase. More importantly, SHM systems that have been installed and in operation from the beginning of an assets' life have the ability to capture comprehensive baseline data prior to the structures' commissioning. This allows for more straightforward analysis of structural performance throughout the continued monitoring of the asset while it is in service.

This study is focused on SHM systems installed on new bridges, herein referred to as integrated SHM systems as they consist of sensor networks integrated within the design and construction phases. There have been a variety of other studies in the literature that have assessed integrated SHM systems for use in bridge evaluation and monitoring.

A study conducted by Tennyson et al. (2001) highlighted a number of case studies where SHM systems incorporating fibre optic sensors (FOS) were installed during the construction of new bridges. The $12.9 \mathrm{~km}$ long Confederation Bridge which connects Prince Edward Island to New Brunswick in Canada was instrumented with fibre optic sensors based on Bragg gratings (FBGs). A total of 12 FBGs were installed on reinforcing bars cast within one of the spans of the concrete box sections which compose the bridge superstructure. This system was installed in order to monitor its inservice behaviour shortly after construction was completed. In addition to FBGs, a variety of other instruments were installed to measure impact loads due to ice flows, deformations, temperature, wind and seismic vibrations and corrosion (Cheung et al. 1997).

In Stockholm, the (new) Årsta Railway Bridge completed in 2005 incorporated both traditional strain gauges and fibre optic sensors during its construction (Jemli et al. 2003). The new bridge consists of ten 78-metre spans carried by prestressed concrete u-shaped box girders. The new structure was considered to be most vulnerable during the construction phases and therefore, an integrated SHM system was chosen.
In addition to short term monitoring, both long term static and dynamic monitoring was conducted. A combination of long gauge fibre optic sensors and more traditional strain transducers were deployed within several spans and at several locations along the bridges' cross-section. Jemli et al. (2003) note the complexities of installing and operating a SHM system during the construction of a bridge specifically in regards to coordination with other on-site construction activities. Their results indicated good agreement between the fibre optic sensor and the strain transducer measurements.

Another large-scale study conducted by Chana et al. (2006) evaluated the performance of a new monitoring system also based on FBGs. However, this FBG-based system was installed after the bridge had been in service. They compared their results to results obtained from a previously installed SHM system that was in operation since the bridge opened in 1997. The original Wind and Structural Health Monitoring System (WASHMS) included accelerometers, strain gauges (110 in total), displacement transducers, level sensors, anemometers, temperature sensors and weigh-inmotion sensors. They concluded that the FBG sensors installed could provide a rich variety of information that could be used to carry out both static and dynamic strain sensing and their results compared well to those of the WASHMS strain gauges.

A more recent study reported by the US Federal Highways Administration (FHWA) presents the case for installing sensors in bridge substructures during construction using the newly constructed I-35W highway bridge in Minnesota as a case study (Collins et al. 2014). Both strain gauges and temperature sensors (thermocouples) were installed in two of the main bridge drilled shafts (pier footings) during construction. The internal temperature development within the mass concrete shaft was monitored during the concrete curing process. They noted significant temperature differences between the concrete at the edges and the centre of the shaft. Further monitoring of the pier footings was undertaken during the remaining construction stages including a live construction load test. Under these test conditions they were able to detect torsional effects in the footing cap through the measured tension in one of the pier 
footings. Strain gauges were also installed on some of the main superstructure elements however, no results were available at the time the report was published.

These case studies demonstrate an established knowledge base for integrated sensing systems installed during the construction phases of bridges while identifying that much work and research is still required to make these types of systems more commonplace in new structures. The following study focuses on developing a robust fibre-optic sensing system for pre-commission monitoring and demonstrates the feasibility of having such systems regularly installed in new bridges as a long term performance monitoring tool. Specifically, it seeks to use this sensor system to understand the behaviour of a composite concrete-steel girder system from its construction to inform long term assessment.

\subsection{The Stafford Area Improvements Programme}

As part of a $£ 250$ million rail improvements scheme, the Stafford Area Improvements Programme located in the Midlands region in the UK involves the construction of ten new bridges. The scheme is aimed at upgrading existing rail lines and providing a grade separated junction to increase overall capacity along the West Coast Main Line (WCML). A more detailed description of the project is described in Gibbons et al. (2015). Out of these new bridge structures, this study describes the instrumentation of a 26.8 metre Network Rail 'E-type' steel half-through bridge designed to carry two new rail lines over the existing WCML. Construction of the bridge began in December 2014 with the construction of the concrete pile foundation and is scheduled to open to commercial rail traffic in April 2016.

It is the first time in the UK where a bridge has been instrumented with fibre optic sensors in such detail from the beginning of its constructed life. Specifically, this paper presents in great detail the real-time development of strains within the main bridge girders during the casting and curing of the reinforced concrete deck. This work is part of a larger study to investigate long term railway bridge response using integrated fibre optic sensing and demonstrates the value of the detailed data captured using integrated SHM systems.

\section{Description of Structural System}

The bridge instrumented as part of this work is referred to as Intersection Bridge 5. The superstructure includes a pair of I-shaped steel girders, a reinforced concrete composite deck supported on an array of cross girders. The main girders are pre-formed to produce a camber and include a series of transverse stiffeners and top and bottom flange doubler plates. The bridge is simply supported at the ends of the main girders on four bearing plinths. A schematic of the main superstructure is presented in Figure 1 and the completed structure is shown in Figure 2.

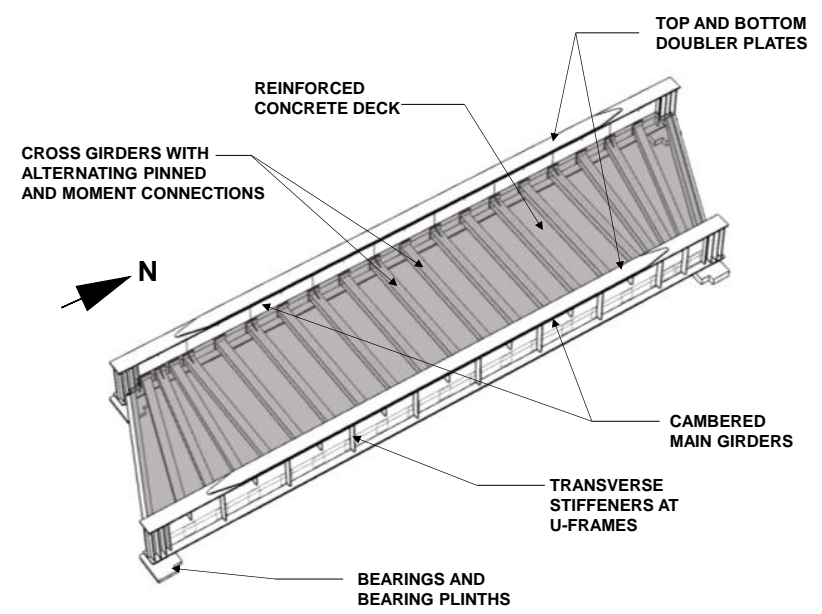

Figure 1. Schematic structural layout of Intersection Bridge 5.

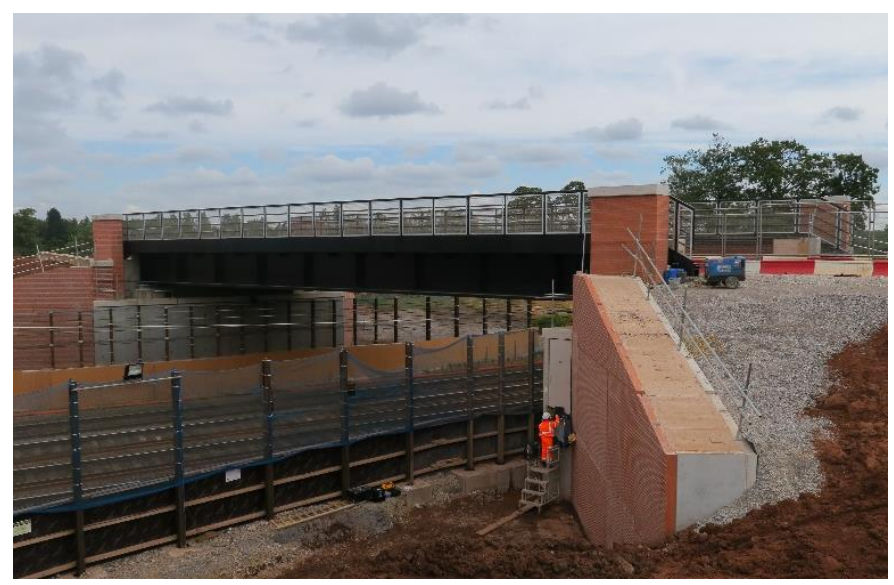

Figure 2. Completed Intersection Bridge 5.

The main steel superstructure (complete with pedestrian walkway) was prefabricated and stored 
temporarily adjacent to the bridge abutments. During a weekend rail possession of the WCML, the entire superstructure was lifted onto the abutments. Permanent glass fibre reinforced formwork was used to form the soffit of the reinforced concrete deck and top and bottom steel reinforcing mats were installed prior to casting of the concrete deck. Following completion of the main superstructure, the concrete deck was temporarily protected with timber sheeting and covered with granular fill to allow the bridge to form part of a temporary haul road used for the major earth moving operations associated with the project.

\section{Description of Fibre-Optic Monitoring Network}

Aside from its data capture capabilities, an effective integrated SHM system must also be both economically and logistically feasible to install during the construction of an asset. The structural sensing system used on this project is based on fibre optic technology. Fibre optic sensors based on Bragg gratings were chosen for their ability to be multiplexed along a single optical fibre (up to 20 sensors), their non-corrosive and non-conductive nature, their ability to measure strain dynamically (sampling rates up to $1 \mathrm{kHz}$ ), and the flexibility to outfit their packaging for increased robustness. The FBGs using on this project were manufactured using a draw tower process with low bend loss fibre and a GFRP-based coating for added robustness. To compensate for temperature induced strains, separate unbonded FBG temperature compensating cables were installed alongside the strain cables. Data acquisition rates of up to $250 \mathrm{~Hz}$ can be achieved with strain resolutions within \pm 10 microstrain.

Bragg gratings are dielectric mirrors inscribed on the surface of an optical fibre. These mirrors only reflect light pulses at a particular wavelength. Once the fibre is strained, the reflected wavelength shifts and can be correlated to strain (Grattan and Sun, 2000). Equation (1) describes the process by which FBG wavelength shifts are converted to strain changes that also compensate for temperature effects and thermal strain changes.

$$
\Delta \varepsilon_{M}=\frac{1}{k_{\varepsilon}}\left[\left(\frac{\Delta \lambda}{\lambda_{0}}\right)_{S}-k_{T} \frac{\left(\frac{\Delta \lambda}{\lambda_{0}}\right)_{T}}{k_{T_{T}}}\right]-\alpha_{\text {conc }} \frac{\left(\frac{\Delta \lambda}{\lambda_{0}}\right)_{T}}{k_{T_{T}}}
$$

Where,

$\Delta \varepsilon_{\mathrm{M}} \quad=$ change in mechanical strain

$\left(\Delta \lambda / \lambda_{0}\right)_{s}=$ change in relative wavelength of strain sensor

$\left(\Delta \lambda / \lambda_{0}\right)_{T}=$ change in relative wavelength of temperature compensating sensor

$k_{\varepsilon} \quad=$ gage factor, provided by strain FBG manufacturer

$\mathrm{k}_{\mathrm{T}} \quad=$ experimentally derived constant for FBG temperature compensating sensor

$\mathrm{k}_{\mathrm{TT}} \quad=$ change of the refractive index of glass

$\alpha_{\text {sub }}=$ linear coefficient of thermal expansion of substrate $\left(/{ }^{\circ} \mathrm{C}\right)$

Strain conversion procedures like the one presented above have been well documented in the literature (Kreuzer 2006).

FBG sensors were installed along the top and bottom flanges of both main girders. Additional routing cables were spliced to the main sensor cables and terminated in a central cable enclosure mounted at the side of the bridge abutments where monitoring equipment was set up. Figure 3 depicts the locations of where FBG sensor cables were installed on the main girders.

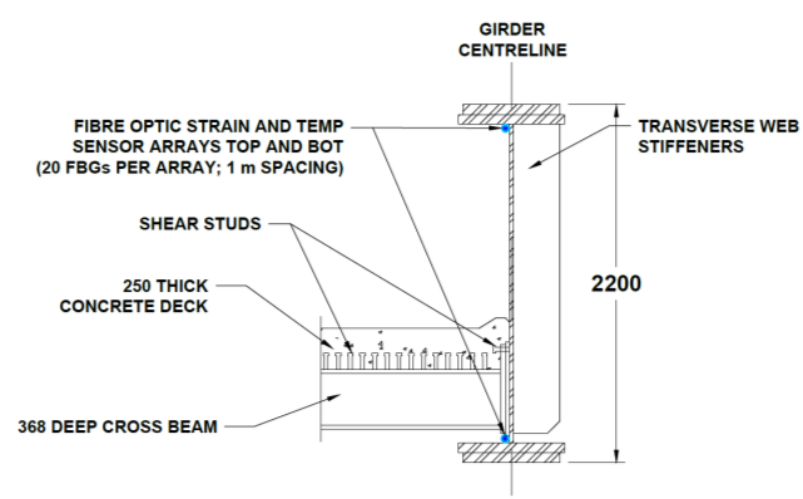

Figure 3. FBG sensor layout on typical main girders.

Deployment of the sensor network took place over a three day period in May 2015 and a two day period in July 2015 immediately prior to casting of the concrete deck. The main superstructure sensor cables were attached to the underside of the top flange and on the top surface of the bottom flange in both the main girders. A high strength two-part 
epoxy was used to bond the cables to the steel surfaces. The FBGs installed in the concrete deck were attached to the top layer of transverse reinforcing using plastic cable ties spaced at approximately $300 \mathrm{~mm}$ centres. A total of 160 FBG sensors (temperature and strain) were installed on the main bridge girders.

Due to the high-paced nature of the bridge construction schedule, all sensor cables were prepared prior to going to site to expedite their installation. This included labelling, measuring and splicing the main sensor cables to routing cables. In addition, a set of studies were undertaken to improve overall robustness of the sensor system using the laboratory facilities at the University of Cambridge. These included developing speciallyfabricated flexible splice protectors and undertaking controlled calibration experiments for determining factors outlined in equation 1 . The prepared sensor cables ready for deployment on site are shown in Figure 4.

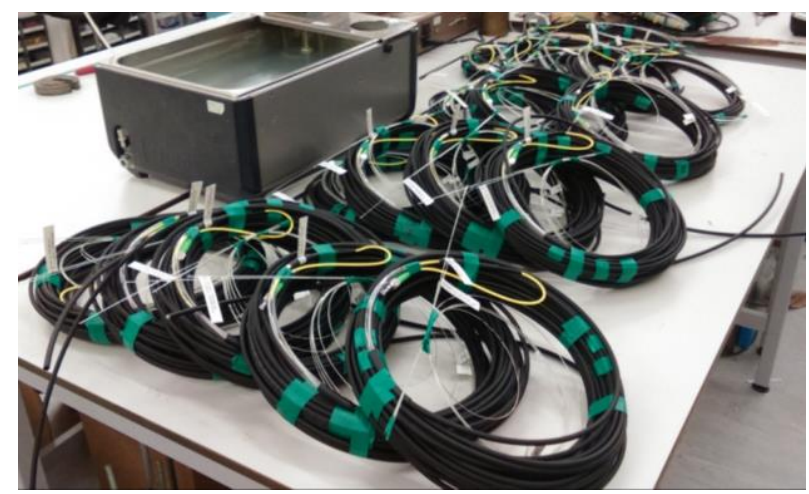

Figure 4. Laboratory prepared FBG sensor cables.

\section{Results and Discussion}

The following section describes the measurement results recorded during the casting and curing of the concrete deck.

As a result of the laboratory preparation and additional development work performed prior to sensor deployment, the integrated SHM system proved to be highly robust. Out of the 160 sensors installed, only two malfunctioned following their installation. This was attributed to an optical power loss due to a micro bend in the splice connection between the routing and sensor cables.
Several stages of monitoring were undertaken during the deck casting and curing operations. The entire deck casting process (approximately 4 hours) was monitored with readings taken once every second $(1 \mathrm{~Hz})$. The curing process was monitored with readings taken once every minute $(1 / 60 \mathrm{~Hz})$.

Figure 5 is used to illustrate the various monitoring stages undertaken. Following casting, there was an approximate two hour period where there was a long delay in the delivery of concrete and therefore, data acquisition was interrupted and resumed afterwards. Curing was monitored starting at approximately 12:45pm on 3 July 2015 and continued until 8:00am on 13 July 2015. Figure 5 also depicts a large three day gap in the curing monitoring data which was due to a power cut over a weekend period. Curing monitoring subsequently continued for the remaining 7 days. A clear distinction between top (negative = compression) and bottom (positive = tension) strains is discernible for the duration of the monitoring. Following initial casting, there is a consistent diurnal variation in strains that varies between 10 and 50 microstrain for the bottom flange and between -45 and -130 microstrain for the top flange. Although the strain values reported have been compensated for temperature effects, it appears that some latent effect of temperature is still influencing the results. The top of the girder is exposed to direct sunlight whereas the bottom is in constant shade. Therefore, the observed strain variations between the top and bottom girder indicate that temperature may still be influencing the results. Additional discussion of the thermal effects transferred from connected structural elements is discussed in more detail in Section 4.1.

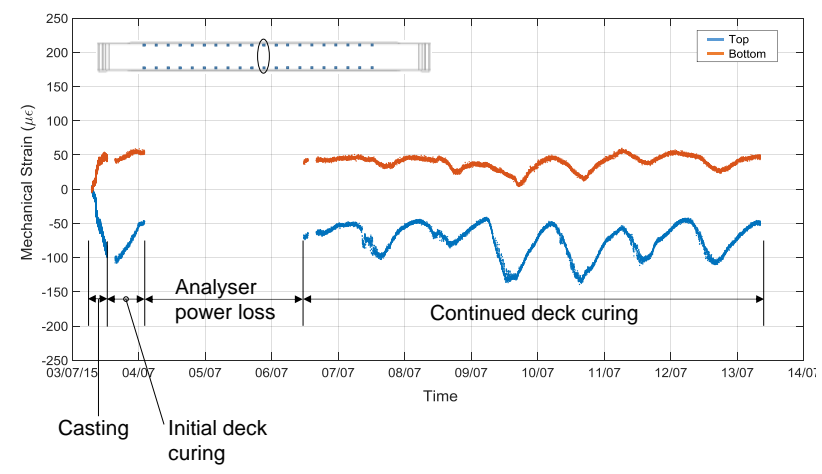

Figure 5. Overview of monitoring stages (West main girder mechanical strain development during 
deck casting and curing; baseline=pre-deck casting; positive strain indicates tension)

\subsection{Sequential casting of the concrete deck}

As previously described, the deck casting took place over approximately four hours. Concrete was placed using a portable pumping vehicle fitted with an articulated nozzle. A detailed record of the casting sequence along with the recorded ambient weather conditions is presented in Figure 6. There were eight separate casting stages representing periods of time between concrete pump refilling. Real time strain development within both main girders was recorded for the entire casting process. Data was collected every second $(1 \mathrm{~Hz})$ for each FBG sensor (80 FBGs per girder) which provided a highly detailed view of each girders behaviour.

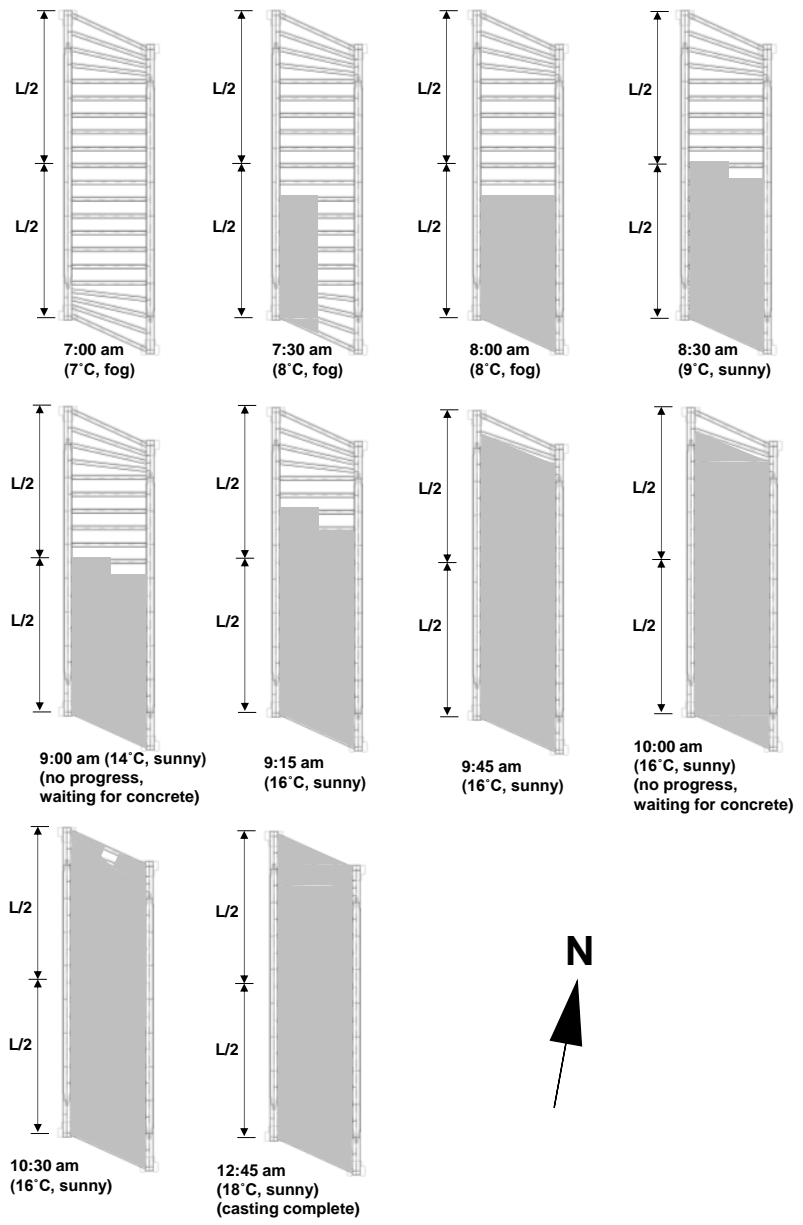

Figure 6. Deck casting sequence and recorded ambient temperature data.

Figure 7 presents the top and bottom strain profiles at each stage of the deck casting sequence. Note that the strain data presented has been compensated for temperature changes and thermal strain changes in the main girder using equation 1. During the monitoring process it was noticed that the last sensors on the main east girder were malfunctioning and therefore, data is not available for these sensors during monitoring of the deck casting or curing (refer to Figure 7).

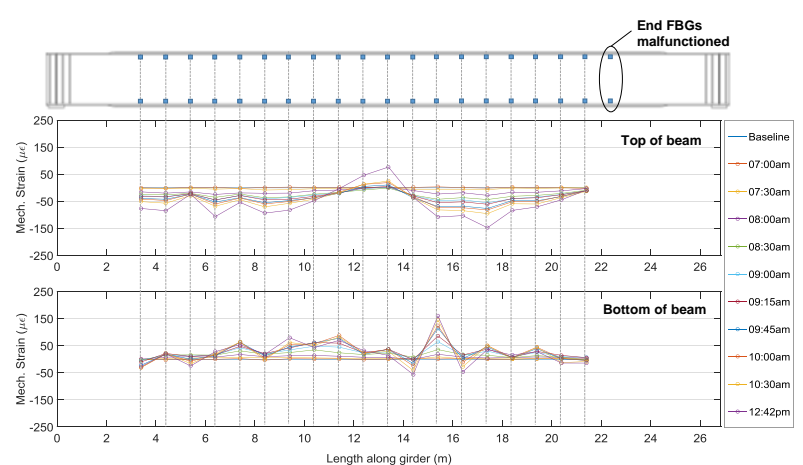

Figure 7. Evolution of strain profile during deck casting for the East Main Girder (baseline = pre deck casting; positive strain indicates tension)

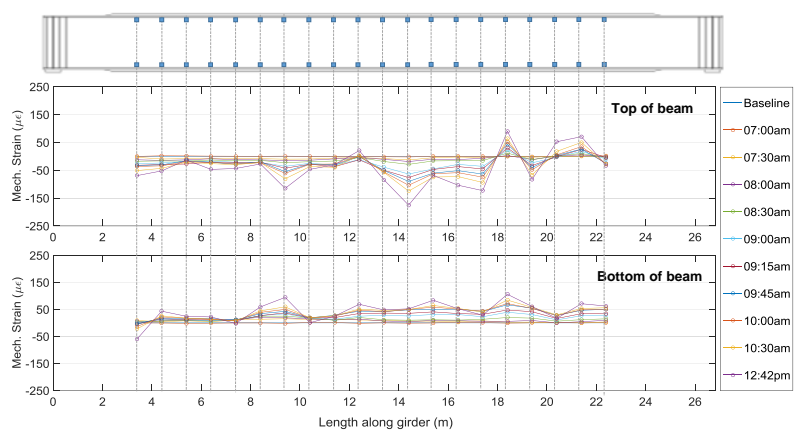

Figure 8. Evolution of strain profile during deck cast for the West Main Girder (baseline = pre-deck casting; positive strain indicates tension).

Overall, it appears that both girders exhibit fairly similar behaviour as the deck casting progresses where additional compression and tension is introduced into the top and bottom flanges, respectively. The data also reveals sections along the beam where the strain profile is non-uniform, that is, the top flange appears to be placed in tension (or experiences a reduction in compression) during certain stages and the bottom flange undergoes compression (or experiences a reduction in tension). There may be several reasons to explain the data described in Figure 5, Figure 7 and Figure 8. Firstly, it is important to note that since the sensors were installed on the pre- 
assembled superstructure, they are incapable of accounting for the self-weight of the superstructure itself. Therefore, the mechanical strains recorded only include the additional strain change due to the concrete casting and curing processes.

Secondly, while the measured strain in the girder has been compensated for the effects of temperature by 1 ) accounting for the change in the refractive index of glass due to temperature for the sensor and, 2) by subtracting the thermal strains (expansion and contraction) from the total strain to give the mechanical strain, this only accounts for temperature effects acting on the main girder. The thermal strain is determined by multiplying the thermal coefficient of the substrate (i.e., steel) by the change in temperature (refer to equation 1 ). Therefore, this measured strain represents the uniaxial thermal strain contribution of the main girder but does not account for the effect of loading (mechanical or thermal) induced by other connected elements in the structure. The composite concrete deck attached to the web of the main girder will transfer independent diurnal thermal loads and loads due to restrained concrete shrinkage to the main girders. That is to say, the thermal response a given structural member (such as the main girder) experiences under its own thermal expansion and contraction can be corrected using simplified relationships for thermal strain. However, the three-dimensional composite thermal response of the entire structure will also apply a load to the main girder, which will not be accounted for by only considering the uniaxial temperature effects measured by the sensors. The consideration of these multiple dependent and independent effects demonstrates the complex nature of the thermal loading on the structure.

\subsection{Curing of the concrete deck}

Following casting of the concrete deck, sensor readings were acquired for another seven days to record the effects of deck curing on the strains within the main girders. Figure 9 and Figure 10 present the strain development along both the east and west main girders, respectively for the first seven days after deck casting. Note that the strain changes presented are with respect to the original pre-deck casting baseline, that is, they represent incremental strain values. To provide consistency in the reported results, the strain profiles reported all correspond to sensor values reported at $12: 00 \mathrm{pm}$ on each day of curing. While the strain profiles within both girders seem to fluctuate along their lengths, their distribution seems to be similar to those captured at the end of the casting process (i.e., similar locations of peaks and valleys). This infers that these are permanent strains developed within the girders due to the casting and curing of the concrete deck. As described above, the mechanical strain results presented do not include the self-weight of the main superstructure elements and therefore, the strains presented do not represent the absolute strain within the girders. In addition, the secondary thermal effects due to the connected concrete deck (as described above) are not accounted for within the reported mechanical strains.

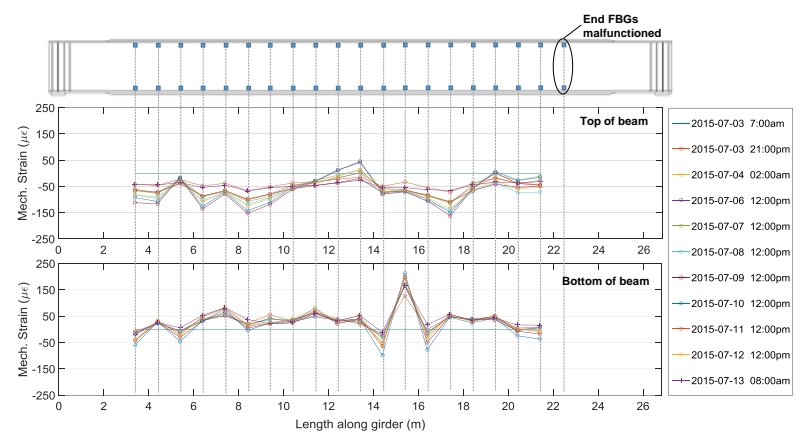

Figure 9. Evolution of strain profile during deck curing process for the East Main Girder (baseline = pre deck casting; positive strain indicates tension).

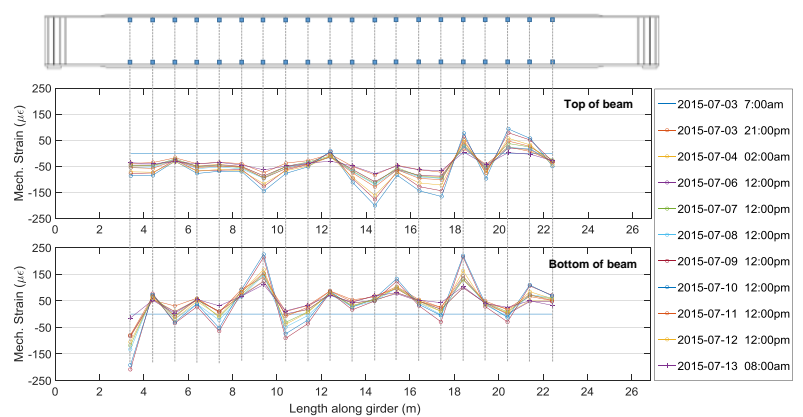

Figure 10. Evolution of strain profile during deck curing process for the West Main Girder (baseline = pre deck casting; positive strain indicates tension).

\section{Conclusions}

This study presented the development and deployment of a fibre-optic based sensing system 
on a newly constructed railway bridge in the UK. The system is capable of providing a highly detailed profile of strain changes during several construction phases. Overall, the sensor network proved to be highly robust during its installation and required approximately one week in total to install. The highly complex process of strain development within the main girders during the staged concrete casting and curing sequence was captured using the sensor system. Based on the measured results, the permanent strains developed with the girders at the end of 7 days of curing remained non-uniform and the highly complex three-dimensional thermal strain transfer present within the structure was revealed.

Future work will include further monitoring of various construction sequences with a view to creating a comprehensive report on the state-ofthe-asset prior to commissioning. This report will serve as a benchmark by which long term in-service (i.e., commercial rail traffic) strains within the structure can be readily tracked and compared with the benchmark data. Integrated SHM systems of this type are powerful tools that allow the complete load history of a structural element to be captured from the beginning of its life.

\section{Acknowledgements}

The authors gratefully acknowledge the EPSRC and Innovate UK for funding this research through the CSIC Innovation and Knowledge Centre (EPSRC grant reference number EP/L010917/1); the on-site assistance of Jason Shardelow of CSIC and Jules Birks of Mott Macdonald (formerly of CSIC); the technical assistance in sensor development and procurement of Cedric Kechavarzi and Philip Keenan of CSIC; James Oliver, Matthew Timmis, Brad Stanaway and Phil Holland of Laing O'Rourke, and Ruth Platt and Mike Henwood of Atkins, for providing their invaluable support for this project.

\section{References}

[1] Webb G. Structural Health Monitoring of Bridges. PhD Thesis, University of Cambridge. 2014: 204 pages.
[2] Tennyson R.C., Mufti A.A., Rizkalla S., Tadros G. and Benmokrane B. Structural Health Monitoring of Innovative Bridges in Canada with Fibre Optic Sensors. Smart Materials and Structures. 2001; 10: $560-573$.

[3] Cheung M.S., Tadros G.S., Brown T., Dilger W.H., Ghali A., and Lau D.T. Field Monitoring and Research on Performance of the Confederation Bridge. Canadian Journal of Civil Engineering. 1997; 24: 951 - 962.

[4] Jemli M.E., Karoumi R., and Lanaro R. Monitoring of the New Årsta Railway Bridge Using Traditional and Fibre Optic Sensors. Smart Structures and Materials. 2003; 5057: $279-288$.

[5] Chana T.H.T., Yua L., Tamb H.Y., Nia Y.Q., Liub S.Y., Chung W.H., and Cheng L.K. Fiber Bragg Grating Sensors for Structural Health Monitoring of Tsing Ma Bridge: Background and Experimental Observation. Engineering structures. 2006; 28: 648-659.

[6] Collins J., Mullins G., Lewis C., and Winters D. State of the Practice and Art for Structural Health Monitoring of Bridge Substructures. U.S. Department of Transportation Federal Highways Administration Report FHWA-HRT09-040. 2014: 100 pgs.

[7] Gibbons N., Butler L., Williamson M., Ellwood A., Platt R., Oliver J., Henwood M., Holland P., Dirar S., Arthurs S., Middleton C., and Elshafie M. Monitoring the Early-Age Behaviour of Prestressed Concrete Beams Using Fibre Optic Sensors. $16^{\text {th }}$ European Bridge Conference, Edinburgh. 2015: 11 pgs.

[8] Grattan K.T.V. and Sun T. Fiber Optic Sensor Technology: An Overview. Sensors and Actuators. 2000: 82: 40 - 61 .

[9] Kreuzer M. Strain measurement with fiber Bragg grating sensors. HBM, Darmstadt, S2338 1.0, 2006. 